Ralf Lillbacka, $\mathrm{PhD}$ in Political Science and a Senior Lecturer in the Sector of Social Services and Health Care at Novia, Finland

\title{
Special Operations Principles and Finnish Long Range Patrols during WWII
}

\section{Key words}

special operations principles, Finnish long range patrols, World War II, McRaven, LISREL path model

\begin{abstract}
The study assessed whether the six special operations principles (simplicity, security, repetition, speed, purpose, and surprise) proposed by Admiral William McRaven could predict the degree of success among Finnish long range patrols during WWII. Eighty-four missions that included deliberate contact with the enemy were considered. Bootstrapped estimates were obtained from a LISREL path model. The result offers partial support for McRaven's model. Significant direct and indirect effects of security, purpose and surprise were demonstrated. Limitations imposed by available data, as well as the circumstance that other principles were rarely violated, may explain the absence of further significant effects. It is furthermore suggested that the principles can be divided into "decisive" (security, purpose, and surprise) where negligence has immediate detrimental consequences, and "contextual" (simplicity, repetition, and in part, speed) that are largely case-specific and may need further precision to be analytically viable. The cause for the absence of significant effects would according to this interpretation be that the principles, as they are generally defined, fail to identify contextual circumstances that are crucial for success.
\end{abstract}

\section{Introduction}

How can operations that seemingly defy fundamental military logic, such as a numerically inferior force attacking a larger fortified force, still be successful? The question of whether there are principles that may, if not 
ensure victory, at least facilitate success has been paramount since the birth of modern military theory in the wake of the Napoleonic Wars. Viewpoints range from claims that each situation is unique and cannot be reduced to simple rules, to claims that despite technical and tactical development, some principles are eternal. (See e.g. Alger 1982: 16 ff) Yet, among numerous aspects considered, special operations have largely eluded theoretical scrutiny. (McRaven 1995: 1) Modern military doctrine encompasses principles that are very similar to those introduced two centuries ago, and neither seemingly allows much room for special operations.

Special operations have become particularly important in the post-Cold War environment of asymmetric conflicts, where unconventional enemies are increasingly countered by small unit tactics (see e.g. Hammes 2005: 269-272; Scales 2005: 41-57), and where terrorists have adopted similar tactics (see e.g. Morris 2009). Apart from contemporary relevance, as "anomalous" cases, special operations may critically challenge and advance military theory. However, this paper does not attempt to advance the more general discussion concerning principles of war. Instead, it considers the principles identified by Admiral McRaven, currently Commander of the United States Special Operations Command, in his book "SPEC OPS. Case Studies in Special Operations Warfare: Theory and Practice" (1995), i.e. surprise, purpose, security, simplicity, repetition, and speed, presumed to pertain to special operations.

The aim is to test whether these six principles can predict the rate of success among Finnish long range patrols during WWII. The study adopts a rarely used approach in this area, i.e. statistical analysis, and considers eighty-four cases that included deliberate contact with the enemy. Whereas case studies are common, there has been no extensive study to empirically validate principles of war. (Ångström \& Widén 2012: 279280) Statistical analysis has apparent limitations, such as very extensive demands on data, or being too blunt to grasp very complex events, but can on the other hand critically test specific propositions regarding trends. The notion of principles of war does by no means presuppose that 
identical situations would always generate identical results, as individual cases may differ vastly from any general trend (and would be more properly studied with qualitative methods), but it does presuppose that situational parameters would tend to generate certain observable propensities.

The study will not consider special operations as parts of a larger counterinsurgency effort that also includes political, social and economic aspects (see e.g. Johnson et al. 2010: 230-235; Metz 2005; Hoffman 2005), nor the political constraints of low intensity conflicts (see e.g. Tovy 2009: 59-60), since the focus is placed exclusively on tactical or battle-technical success.

During the so called Continuation War 1941-1944, patrol warfare was common in the sparsely populated, vast woodlands north of Lake Ladoga, requiring designated troops for deep reconnaissance and strikes in Soviet rear areas. Apart from other limitations detailed below, the records held by the Finnish National Archive are not complete. (Saressalo 2010: 104105) The author is very much indebted to the work of Lassi Saressalo, who has reconstructed mission profiles e.g. through interviews with WWII veterans, and presented his results in the book "Päämajan kaukopartiot jatkosodassa" [The Headquarter's Long Range Patrols in the Continuation War]. Saressalo's access to documents and aid by Finnish veterans' associations render it unlikely to be surpassed by any renewed inquiry, and his findings constitute the primary source of data for this analysis.

\section{The "principles of war" in military doctrine}

Modern military theory's concern with principles of war began in the 1830s. In contrast to his contemporary, Antoine Henri de Jomini, Carl von Clausewitz opposed inflexible principles and considered every situation unique; principles should be heuristic devices to guide selfeducation and avoid pitfalls rather than a rigid manual. Consequently, he advocated critical case studies to cultivate the commander's "genius", an 
innate talent that cannot be defined by rules. (von Clausewitz 2007: 8991, 101, 106-130; Alger 1982: 16-32; Echevarria 2005: 61-62; Hammes 2005: 264) His notions resemble how current military training aims to aid decision-making during combat. (Compare e.g. to Bryant 2004; Phillips et al. 1998; Marr 2001)

Combat is inherently unpredictable, von Clausewitz argued, and the "friction of war" (unpredictable, accumulating, random difficulties caused e.g. by enemy action, weather, and accidents) conspires against any strategy. (Von Clausewitz 2007: 17-30, 65-68, 252-258; see also Johnson et al. 2010: 12-13) Hence, von Clausewitz considered defence inherently stronger than offence, as time works against an attacker. The "friction of war" will successively diminish even a superior attacker's force until it eventually reaches a "culmination point" where it is exhausted. Consequently, simple plans have a better chance of success, and forces should be concentrated at a decisive point, and not split unless absolutely necessary. (Von Clausewitz 2007: 24-25, 147-148, 151, 159-162, 197198; see also Johnson et al. 2010: 11-13) Despite their somewhat different perspectives, the end result is similar, since de Jomini (2007: 52-53) also emphasized manoeuvre and massing forces at decisive points. However, von Clausewitz distrusted unconventional warfare methods or "ruses" as insufficient to accomplish decisive conclusions (Johnson et al. 2010: 12), whereas de Jomini (2007: 159-167) noted that independent detachments could affect the outcome of larger strategic operations, but remarked that "ordinary rules are not applicable to them".

The continuity is evident in current US doctrine (Department of the Army 2012: 4-1 - 4-9), where von Clausewitz's key concepts are highly integrated. Notably, the principles of war are described as heuristic devices in the sense that von Clausewitz intended. Although having been continuously challenged, the principles of war became institutionalized during WWI as means to explicate military knowledge during training. (Lanir 1993; Ångströn \& Widén 2012; see also Alger 1982: 97 ff.) 
In fact, the nine "traditional" principles that became doctrine in the British and the US Army largely resemble von Clausewitz's notions. (Echevarria 2005: 61-62; see also Hammes 2005: 265-266; Alger 1982: 106-145) US Army doctrine lists the following principles of war (principles for operations other than war not included): (1) "Objective", having a clear aim; (2) "Offensive", to seize, retain and exploit the initiative; (3) "Mass", concentrating forces or effects; (4) "Economy of force", using sufficient forces to tie down local enemies to allow massing elsewhere; (5) "Manoeuvre", achieving a positional advantage; (6) "Unity of command", i.e. a unified command structure; (7) "Surprise", overcoming the enemy through unexpected means; (8) "Security", denying the enemy intelligence about deployment and capabilities; (9) "Simplicity", using uncomplicated plans to reduce the element of chance. (Department of the Army 2012: 4-1 - 4-2; Department of the Army 2011: A-1 - A-3; Echevarria 2005: 64-69; Hammes 2005: 266-267; Tovy 2009: 56)

The doctrines of the former USSR, France and Peoples' Republic of China similarly emphasized concentration of force, initiative/manoeuvre, and surprise. "Mobility" and "tempo" in Soviet doctrine corresponded to offensive, and the concept of "deep battle", i.e. simultaneous attacks throughout a battlespace, aimed at overcoming the inherent strength of defence and the "culmination point" addressed by von Clausewitz. (Hammond 2005: 116-117; see also Lanir 1993: 3; Ångström \& Widén 2012: 269; Alger 1982: 149-163; Johnson et al 2010: 10-11; Glantz 1991a; Glantz 1991b; Harrison 2001; Ministry of Defence 2010: 2A-1 2A-6) Current US doctrine emphasizes aspects that are typical of deep battle, e.g. sustaining tempo and initiative, as well as engaging the enemy in depth in a synchronized manner. (Department of the Army 2012: 2-1 2-4, 2-14)

The emergence of asymmetric conflicts and the technological development have raised questions whether the principles are still viable. (For a discussion, see e.g. Malay 2009; Ettrich 2005; Echevarria 2005: 63) Nevertheless, military doctrines continue to emphasize what von Clausewitz even considered the most important principle (See e.g. 
Johnson et al 2010: 10-11), i.e. concentrating overwhelming force (or effect), through surprise and/or manoeuvre, to ensure superiority at a vulnerable centre of gravity, usually a geographical location.

\section{Special operations principles}

As special operations, where a smaller force overcomes a larger and/or prepared and entrenched enemy, by definition contradicts the logic of manoeuvring a superior force against a centre of gravity, McRaven (1995) found that the traditional principles of war did not pertain and consequently developed an alternative set. Whereas the official US joint doctrine includes psychological operations, civil affairs and reconnaissance in special operations (United States Special Operations Command 2011: II-5 - II-20), McRaven's (1995: 2-3) definition is limited to direct action, i.e. "A special operation is conducted by forces specifically trained, equipped, and supported for a specific target whose destruction, elimination, or rescue (in the case of hostages), is a political or military imperative", which is conducted against a prepared defensive position. The joint doctrine (United States Special Operations Command 2011: II-5 - II-7) describes direct action as "time-sensitive" shortduration and small-scale offensive actions, where specialized capabilities and operational techniques are used to achieve certain objectives, and by so doing, Special Forces may use “...raids, ambushes, or other direct assault tactics (including closequarters combat); emplace mines and other munitions..." After accomplishing its task, the force is usually immediately withdrawn from the objective.

Based on eight historical case studies, McRaven (1995: 1-4, 8-11) identified the six principles that allow an attacker to establish "relative superiority", a necessary but not sufficient condition for success. The six principles are:

Simplicity reduces the "friction of war", i.e. the element of chance, by limiting the number of objectives, acquiring good intelligence, and applying (technological) innovations. A complicated plan will require a 
lengthy and consequently a more hazardous execution. (McRaven 1995: 9-14, 62)

Security denies the enemy knowledge about capabilities, the timing and the method of attack, and hence, the opportunity to modify defences. (McRaven 1995: 9, 14-15)

Repetition is necessary not only to rehearse the execution in advance but also to identify weaknesses in the plan, e.g. possible equipment failure. To some extent, general training can substitute rehearsal of a particular operation. (McRaven 1995: 9-10, 15-16, 64-65, 108-109, 194, 280; Tovy 2009: 58)

Surprise means applying timing, an original method of attack, and deception in a manner that prevents even a prepared defender from responding effectively by limiting the defender's freedom of action.

Consequently, security is vital for achieving surprise. Surprise is a necessary but not sufficient condition for achieving relative superiority, since necessary means to defeat the enemy must also be deployed. Accurate and reliable intelligence is usually required for successful surprise attacks. (McRaven 1995: 16-19, 154-155; see also Collins 2002: 83; Johnson et al. 2010: 35; Tovy 2009: 57-61)

Speed includes two aspects, i.e. getting to the objective as fast as possible (avoiding friction underway) and avoiding prolonged contact with the enemy. (McRaven 1995: 19-21) Time usually favours one side. (Collins 2002: 85)

Purpose means having a clear mission statement and a personal commitment to achieving the objective despite obstacles. (McRaven 1995: 21-23)

They are elements of a process, beginning with simplicity during planning, security and repetition during preparation, and surprise, speed and purpose during execution. "...special operations succeed, in spite of their numerical inferiority, when they are able to gain relative superiority 
through the use of a simple plan, carefully concealed, repeatedly and realistically rehearsed, and executed with surprise, speed, and purpose. Failure results when the frictions of war overcome the moral factors." (McRaven 1995: 11)

Relative superiority is achieved when a small attacking force through exploiting some weakness can seize and retain the initiative in a manner that prevents an enemy, even in prepared defensive positions, from utilizing superior numbers. If the attacker is numerically inferior, relative superiority is virtually impossible to regain if lost. Before relative superiority can be obtained, the attacker will traverse an area of vulnerability during which certain key conditions must be achieved. An initial point of vulnerability (where the area of vulnerability begins) is encountered when the attacker risks becoming exposed to enemy counteractions. (McRaven 1995: 4-8; Tovy 2009: 56-57) In a hypothetical example, an attacking force surreptitiously infiltrating an enemy position would encounter a point of vulnerability when it begins to penetrate the enemy's defensive perimeter. The area of vulnerability corresponds to the time needed to deploy without being detected. The key condition for obtaining relative superiority would be reaching positions from where to surprise and defeat the defender.

The combination of these principles explains why special operations are feasible. Whereas large forces may obtain surprise, relative superiority favours smaller forces, as they are less susceptible to friction of war. It is more difficult for large formations to develop a simple plan, keep movements concealed, rehearse operations full-scale while still maintaining security, gain tactical surprise and speed, as well as motivate each individual soldier. (McRaven 1995: 8-9)

Whereas it can be argued that the eight cases discussed by McRaven (1995) differ from the Finnish patrols described below with regard to scope, technical sophistication, and firepower, this would not necessarily imply that these principles would be less pertinent. Rather, since the Finnish patrols suffered not only from vastly inferior numbers, but also 
had to do with light weaponry even when attacking enemy positions, it would seem more appropriate to assume that adhering to these principles would be even more imperative, if relative superiority would be achieved. It can also be noted that the eight cases are quite different with regard to the execution, which mirrors McRaven's notion that these principles pertain in general to special operations. Four cases represent insertion by air (gliders, helicopters, or airplane), i.e. the German attack on the Belgian fort of Eben Emael in 1940, the rescue of Benito Mussolini by German commandos in 1943, the US raid on the prison camp in Son Tay 1970, and the Israeli raid on Entebbe in 1976, of which the first case aimed at neutralizing an enemy installation, and the three others were rescue operations. Three cases were seaborne operations, i.e. the Italian manned torpedo attack at Alexandria in 1941, the British midget submarine attack on Tirpitz in 1943, and the British seaborne raid on Saint-Nazaire in 1943. The US Ranger raid on Cabanatuan in 1945 to free allied prisoners of war was the only case when the attacking force infiltrated by land.

\section{Finnish long range patrols during World War II}

Accuracy of data is always a concern when historical events are accounted for. In this study, where statistical analysis rather than historical description is the primary aim, accuracy is by no means less important. The literature utilized here can largely be characterized as document literature, and was selected for this study as it offers detailed statistics regarding Finnish long range patrols. However, the accuracy of these accounts cannot always be ascertained and various sources might be inconsistent. (Some minor discrepancies in the literature are noted in Appendix 1.) This ties in with the traditional problem of measurement error in statistical analysis, i.e. when variables are imperfect representations of "true scores", which will tend to obscure correlations. (For an introduction, see e.g. Osborne \& Waters 2002) This has methodological consequences, as is described below; the bootstrap analysis adopted in this study offers more robust (and more conservative) estimates when data have disadvantageous properties. However, this is no perfect remedy, and the reader should be aware of the limitations imposed 
by available data. These limitations are in any case more likely to cause so called type II errors (i.e. a failure to identify significant correlations) rather than "false positives".

Finland fought two wars against the Soviet Union during WWII, the "Winter War" from 30 November 1939 to 12 March 1940, and the "Continuation War" from 25 June 1941 to 5 September 1944. After the armistice, the so called "Lapland War" against German forces retreating from northern Finland ensued.

During the Continuation War, Finnish long range patrols operated primarily in the sparsely populated and heavily forested areas north of Lake Ladoga, as the front line on the Karelian Isthmus remained static and impenetrable for most of the war. Their primary task was reconnaissance, but they were also used for direct action missions. (Marttinen \& Tikkanen 2002: 29-30, 36; Saressalo 2010: 13-18)

During the Winter War, long range patrols were not performed, but patrols conducted reconnaissance during the interwar period, and before hostilities officially began in 1941, a patrol was sent to destroy a lock at the Stalin Canal but had to abort. The patrol organization was established on 21 April 1941. It consisted of four detachments, sorting directly under the General Headquarters until 1 July 1943, when it was reorganized into the $4^{\text {th }}$ Independent Battalion (Erillinen Pataljoona 4). Each detachment was named after the commanding officer (Vehniäinen 1/ErP 4, Kuismanen 2/ErP 4, Marttina 3/ErP 4, and Paatsalo 4/ErP 4) and was responsible for a segment of the front; Detachment Vehniäinen being the southernmost and Detachment Paatsalo the northernmost detachment. Part of the latter was initially under the command of the Finnish $6{ }^{\text {th }}$ Division, and another element was during January-September 1942 assigned to the German Kompanie Tromsdorff. The German forces in Finland did not conduct independent long-range patrolling, but participated in joint efforts to gain experience, and often had a supportive role by escorting patrols and establishing patrol bases. (Tikkanen 1996: 10-12, 25-27, 32-36, 40; Marttinen \& Tikkanen 2002: 31-34, 58-66; Saressalo 2010: 19-33) 
The all-volunteer force consisted mainly of 20-24 years old athletes or farmers accustomed to wooded terrain. Recruits either applied or were encouraged to do so, and were expected to be physically and mentally strong, have previous military training, to be patriotic, reliable and disciplined. The first patrol mission was often part of the selection process, after which some were dismissed and some opted to leave. (Marttinen \& Tikkanen 2002: 32-35; Tikkanen 1996: 27, 38-39) Whereas recruits received additional training upon entry and/or had previous combat experience, it seems no patrol ever fully rehearsed a raid. Rather, even designated direct action relied on general training and previous experience.

Security was strict, as basic information was issued only 24 hours in advance. Patrol members were selected and designated for a specific task by the patrol leader, and were informed about the objective only when the patrol was well under way. (Marttinen \& Tikkanen 2002: 37-38) Patrol members were armed with machine pistols or rifles, and personal side arms. Equipment and supplies were carried, and occasionally replenished through airdrops. During summer, small lakes were used to infiltrate patrols by seaplane. Parachutes were only rarely used as an insertion method. (Saressalo 2010: 38-44, 69-89, 96-101)

Most patrols were conducted by squad- or platoon sized elements, but two patrols stand out due to their scope. After a three day long infiltration, a one hundred men strong task force attacked a Soviet supply dump at Petrovskij Jam on 11 February 1942. During a two-hour firefight, they attacked six specific objectives and managed to achieve surprise although a premature rifle shot forced the attack order before all units had deployed. The supply dump was destroyed and the battalion-sized enemy suffered roughly 500 casualties, compared to the attackers' casualties of five dead and six wounded, according to Finnish sources. (Marttinen \& Tikkanen 2002: 145-156; Tikkanen 1996: 17-20, 34-65) Soviet documents suggest a somewhat different outcome, counting 81 Soviet casualties. (Irincheev \& Repnikov 2013: 179-180) Furthermore, as noted 
by Irincheev and Repnikov (2013), two of the designated targets for the Finnish attack were groups of buildings occupied by the Red Army's $2212^{\text {th }}$ Mobile Field Hospital. Whereas it cannot be ascertained that the attackers knew about this before the operation, it became apparent during the attack and was later mentioned in Finnish reports and a subsequent military inquiry. This was later neglected in most Finnish accounts, whereas Soviet accounts neglected the presence of legitimate military targets on the compound. The attack on the hospital highlights a crucial limitation of the quantitative analysis adopted in this paper. Since all planned objectives were achieved, the operation is in a narrow sense considered a complete success, although only part of the structures at one of the objectives were destroyed as intended (Ibid. 116-118), but the destruction of a field hospital is nevertheless a circumstance that questions whether an operation truly can be considered an indisputable success from a more general perspective.

A similar attack at Suopussalmi in March 1944 by "Task Force Kaleva" was founded on poor intelligence, apparently overestimating the target's importance. An element attacking an aircraft observation station at nearby Suopusvaara found the enemy alerted and unsuccessfully tried to come across as a Soviet patrol. At four other objectives, the attack continued for six hours until the last elements disengaged, after aggressive counterattacks by the defenders. The task force suffered five dead and four wounded, whereas the casualties of the defenders were unknown. (Tikkanen 1996: 97-113) Smaller raids cannot be described here, but the patrols considered in this inquiry are listed in Appendix 1.

\section{Methodological considerations and data}

The analysis is limited to patrols where the enemy would be deliberately engaged, which excludes strict reconnaissance. Patrols initiated before the outbreak of the war, or aborted after the armistice, as well as the few patrols conducted during the Lapland War and the patrols of the so called "Kompanie Tromsdorff" have also been excluded. Since these are relatively few, and since controlling for different circumstances requires 
additional parameters, the statistical power of the model would diminish. Hence, I have opted for the methodologically weaker but simpler option to keep such conditions constant by limiting the analysis to Finnish patrols against Soviet forces, initiated and concluded during the state of war.

The availability of data imposes certain limitations. As noted above, records are incomplete since archives were either destroyed or evacuated to Sweden. Complete records are available only for detachment 1/ErP 4 . When reconstructing the activities of other detachments, Saressalo (2010) relied extensively on the recollection by former patrol members. He noted some uncertainties concerning 2/ErP 4 and 3/ErP 4, whereas reconstructed records should be reasonably accurate for 4/Erp 4. (Ibid. 104-105) Minor discrepancies were found when data were compared to other sources, as is detailed in Appendix 1.

A second, more fundamental caveat concerns the validity and reliability of the variables. Notable measurement errors can be rectified by using multiple indicators, but available data will sometimes merely allow a rough approximation of a particular principle. The variables are measured as follows:

Success, the dependent variable, is measured as the proportion of objectives accomplished according to a scale from 0 to 1 . A successful patrol with only one objective would accordingly be coded as 1. An objective is considered accomplished if the patrol fully performs the particular action defined by the mission plan.

Simplicity is measured by the "number of objectives" a patrol was tasked with. For instance, if a patrol was tasked with reconnoitring two areas before derailing a train, the number of objectives is coded as three.

Repetition is measured by the "proportion of patrol members having completed a previous mission". Since missions were not rehearsed, this measurement account for previous training and experience. Preliminary 
tests suggested that e.g. the patrol members' average of previous missions was a less viable measurement. However, data concerning the composition of patrols is highly incomplete and this measurement is accordingly based solely on the partial lists of names identified by Saressalo.

Speed is measured as the "number of days spent in enemy territory", including the day of departure. The time spent in contact with the enemy, which would be a more essential measurement, is mostly unknown. However, few patrols did apparently violate this aspect of "speed".

Security is coded as a dummy variable, where 0 denotes that a patrol avoided detection prior to the first objective that involved deliberate contact with the enemy, and 1 "mission exposed". Exposure to any enemy element before reaching the objective would allow the defender to undertake effective countermeasures, and after any deliberate contact, the defender would be alerted to the presence of a patrol. If a patrol is discovered prematurely by forces at the objective, it is considered a failure to achieve surprise.

Purpose is similarly measured by its opposite, i.e. "change of objective". An aborted mission or an altered objective is coded as 1 , whereas other cases are coded as 0 , also when patrols have several objectives. This ties in with McRaven's (1995: 21-23) view of a mission being carried out to the letter according to the original plan. There is, as is also noted below, a certain redundancy, since it follows that an aborted mission is not successful.

Surprise is measured by the proportion of enemy forces not being prepared to respond when the attack begun. This follows from McRaven's (1995: 4-8) notion of relative superiority. If enemy forces at the objective are alerted to and have deployed to repel the attack before relative superiority is achieved, the attacker has failed to achieve surprise. 
Since four of the indicators (simplicity, speed, security, and purpose) are inversely proportionate to the principles they are intended to represent (similar to negative loadings in factor analysis), the coding might be changed to aid intuitive interpretation. However, I have opted to use the original variable values in order to avoid misunderstandings concerning the direction of the actual correlations.

It would also, when measuring "success", be pertinent to consider how well a patrol can avoid casualties. In an early conception of the statistical analysis, the proportion of casualties suffered by a patrol would have been considered associated with success in a canonical correlation (i.e. correlations between sets of variables rather than between variables). However, this and the more methodologically demanding alternative of using a compound variable turned out to be untenable, since a preliminary test suggested no significant correlation between the casualty rate and success. The bootstrapped correlation (the method is described below) between these two variables was .163 with a standard error of .119 . Accordingly, the reason for not considering casualties in the analysis is primarily technical rather than conceptual, and the accordingly simpler model will have more sufficient statistical power to allow a critical assessment.

It can be argued that a measurement of success that does not account for casualties would have implications for how the variable of "speed" is considered, as it would imply that only the time spent in transition to the last objective would count. However, it is not argued that casualties are irrelevant; rather, this is a limitation imposed by features of available data. Measuring speed as time in transition to the first or the last objective would either demand that aborted patrols were not considered at all (implying a much smaller and biased sample) or a rather arbitrarily censored variable that would also be biased, artificially punishing longer patrols. Whereas the measurement of speed used here has several drawbacks, as is noted below, it is the only tenable methodological option considering the limitations of data. 
Patrol action, apart from reconnaissance, can roughly be categorized into these types: attacks against enemy communications (e.g. derailing trains), ambushes, capturing prisoners of war, and attacks against prepared enemy positions. Patrols frequently had several objectives, e.g. conducting reconnaissance before attacking communications. Appendix 1 lists the coding of the 84 cases, as well as the "patrol numbers" (the patrols of each detachment were consecutively numbered, e.g. patrol number $8 / 2$ refers to the eighth patrol by the second detachment).

Since the aim is to predict the level of success, a regression model is an obvious choice. Preliminary analyses revealed that "surprise" and "purpose" were particularly crucial, which suggested that a path model would be adequate, as it would enable tests whether other principles had independent direct effects or whether the effect was indirect through "surprise" or "purpose". Such a model also ties in with McRaven's (1995: 8-11) view of these principles as a dynamic totality. Hence, the LISREL 9.1 statistical software was used for the analysis. Since the variables are either dichotomous or have a skewed distribution, deviating from the normal distribution required by traditional regression analysis, the bootstrap-option in PRELIS was used to assess estimates. Bootstrapping (a form of resampling) can be used when an underlying distribution is unknown or presumed to deviate from normality. (See e.g. Hesterberg et al 2003: 18-4 ff.) The standard errors obtained from bootstrapping are more reliable and the procedure enables identification of possible biases. The correlations calculated from the bootstrap samples are Pearson's correlations. Polychoric correlations, calculated from ordinal variables assumed to be imperfect representations of an underlying continuous normally distributed variable, would have been a more appropriate choice, but the small sample size and possible redundancies in the data ruled out this option.

One hundred bootstrap samples with a sample fraction of $50 \%$ were created. (The bootstrap samples, based on the data in Appendix 1, can be replicated in PRELIS2 by setting the integer starting value "IX" for the random number generator to 1234567.) As is noted below, despite 
somewhat large standard errors, the estimates appear to be viable. Nevertheless, it should be noted that these limitations of data are likely to induce a bias toward "false negatives". Large measurement errors, regardless of their origin, are likely to obscure a true correlation rather than create a false one, provided they are random.

\section{Results}

The correlation matrix reported in Table 1 was estimated to exclude irrelevant variables and simplify the path model in order to enhance its statistical power. To assess whether an estimate is statistically significant, dividing the estimate with the standard error provides the t-value with 99 degrees of freedom. The limits for the .05 and the .01 levels of significance are 1.98 and 2.63, respectively. As expected, surprise and "change of objective" (purpose) correlate strongly with success, but other correlations seem paradoxical. There is a significant positive correlation between success and number of objectives, and a significant positive correlation between success and "days in hostile territory". The latter cannot be explained as a distortion due to aborted missions being shortened; if these are excluded, the correlation is still positive and statistically significant, i.e. 367 (.144). As is suggested below, the measurements may simply not account for the complexity of an objective and/or reducing the area of vulnerability through circumventing dangerous areas.

The proportion having participated in previous patrols ("repetition") is uncorrelated with all other variables and is excluded from further tests. Incomplete data and inadequate measurement might explain this result, but the variable may also be redundant. As patrol members had received training and usually had previous combat experience, no patrol fundamentally violated the principle of repetition. 
Table 1. Bootstrapped Pearson's correlations ${ }^{\text {a) }}$

${ }^{*} \mathrm{p}<.05,{ }^{*} \mathrm{p}<.01$, the numbers in parentheses are standard errors.

\begin{tabular}{|c|c|c|c|c|c|c|}
\hline & Success & Surprise & $\begin{array}{l}\text { Change of } \\
\text { objective }\end{array}$ & $\begin{array}{c}\text { Number of } \\
\text { objectives }\end{array}$ & $\begin{array}{l}\text { Mission } \\
\text { exposed }\end{array}$ & $\begin{array}{c}\text { Proportion } \\
\text { participated in } \\
\text { previous patrols }\end{array}$ \\
\hline Surprise & $\begin{array}{l}.706^{* *} \\
(.105)\end{array}$ & & & & & \\
\hline $\begin{array}{l}\text { Objective } \\
\text { change }\end{array}$ & $\begin{array}{c}-.520 * * \\
(.118)\end{array}$ & $\begin{array}{c}-.431^{* *} \\
(.150)\end{array}$ & & & & \\
\hline $\begin{array}{l}\text { Number of } \\
\text { objectives }\end{array}$ & $\begin{array}{l}.329 * \\
(.132)\end{array}$ & $\begin{array}{l}.366^{* *} \\
(.114)\end{array}$ & $\begin{array}{l}.004 \\
(.142)\end{array}$ & & & \\
\hline $\begin{array}{l}\text { Mission } \\
\text { exposed }\end{array}$ & $\begin{array}{l}-.278 \\
(.164)\end{array}$ & $\begin{array}{c}-.471^{* *} \\
(.149)\end{array}$ & $\begin{array}{l}.464 * * \\
(.152)\end{array}$ & $\begin{array}{l}-.142 \\
(.106)\end{array}$ & & \\
\hline $\begin{array}{l}\text { Proportion } \\
\text { participated in } \\
\text { previous patrols }\end{array}$ & $\begin{array}{l}.175 \\
(.144)\end{array}$ & $\begin{array}{l}.131 \\
(.164)\end{array}$ & $\begin{array}{l}-.168 \\
(.146)\end{array}$ & $\begin{array}{l}-.079 \\
(.111)\end{array}$ & $\begin{array}{l}-.154 \\
(.150)\end{array}$ & \\
\hline $\begin{array}{l}\text { Days in hostile } \\
\text { territory }\end{array}$ & $\begin{array}{l}.445^{* *} \\
(.132)\end{array}$ & $\begin{array}{l}.369^{*} \\
(.151)\end{array}$ & $\begin{array}{l}-.262 \\
(.151)\end{array}$ & $\begin{array}{l}.372^{*} \\
(.171)\end{array}$ & $\begin{array}{l}-.119 \\
(.161)\end{array}$ & $\begin{array}{r}.100 \\
(.131)\end{array}$ \\
\hline
\end{tabular}

a) The sample fraction is $50 \%$; the number of bootstrap samples is 100. Numbers in parentheses are standard errors.

The path model is reported in table 2. The unexpected relationships noted above cannot be replicated when other variables are controlled for. Neither the number of objectives ("simplicity") nor the days spent in hostile territory ("speed") has any significant effect on success, surprise or objective change ("purpose"). However, whether the mission was exposed ("security") affects both "surprise" and "purpose", and thus indirectly also success. When the paths are examined closer (as the product of the two regression estimates), only the effect via "surprise" is statistically significant on a .05 level of significance. A particularly notable result is the large effect of surprise on success. 
Table 2. Bootstrapped estimates of the path model with success as a dependent variable and surprise and change of objective as intermediate variables ${ }^{\text {a) }}$

${ }^{*} \mathrm{p}<.05, * * \mathrm{p}<.01$, the numbers in parentheses are standard errors.

\begin{tabular}{|l|c|c|c|c|c|c|c|}
\hline \multicolumn{7}{|c|}{ Independent and intermediate variables } & $\mathbf{R}^{2}$ \\
\hline Dependent & Surprise & $\begin{array}{c}\text { Change of } \\
\text { objective }\end{array}$ & $\begin{array}{c}\text { Number of } \\
\text { objectives }\end{array}$ & $\begin{array}{c}\text { Mission } \\
\text { exposed }\end{array}$ & $\begin{array}{c}\text { Days in } \\
\text { hostile } \\
\text { territory }\end{array}$ & \\
\hline Success & $\begin{array}{c}.585 \\
(.142)^{* *}\end{array}$ & $-.308(.154) *$ & .083 & $(.122)$ & $\begin{array}{c}.182 \\
(.128)\end{array}$ & $\begin{array}{c}.136 \\
(.102)\end{array}$ & .655 \\
\hline Surprise & & $.180(.125)$ & $\begin{array}{c}-.410 \\
(.146)^{* *}\end{array}$ & $\begin{array}{c}.203 \\
(.174)\end{array}$ & .367 \\
\hline Change of \\
objective
\end{tabular}

a) The sample fraction is $50 \%$; the number of bootstrap samples is 100 . Numbers in parentheses are standard errors. 


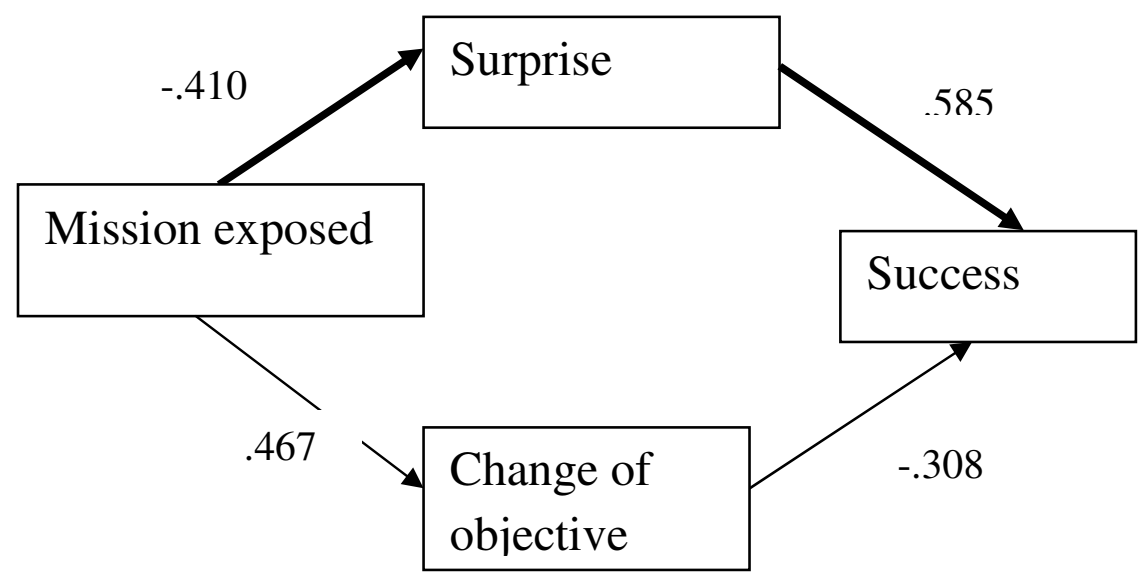

Figure 1. Statistically significant effects in the path model (Note: bold lines indicate a significant indirect effect)

The chief, rather commonsensical findings are illustrated in Figure 1. Maintaining security facilitates surprise, which is essential for success.

An examination of the standard errors, which is not exhaustively presented here, suggests that unexpectedly few estimates seem to be biased. The estimate of the effect of surprise on success is negatively skewed, $\mathrm{Z}=-2.399, \mathrm{p}=.014$, which may partly be an outcome of the strong relationship; outlying bootstrap samples with a weak correlation skew the distribution. Consequently, the model may actually underestimate the role of surprise for success. There is an associated negatively skewed correlation between the error terms of surprise and purpose, $Z=-2.091$, $\mathrm{p}=.037$. A high kurtosis of the effect of simplicity on surprise, $\mathrm{Z}=2.198$, $\mathrm{p}=.028$, may be caused by some deviant bootstrap samples. The largest deviation from normality is associated with the non-significant indirect effect on success by mission exposure (security) via objective change (purpose); the estimate is highly skewed, $\mathrm{Z}=-3.566, \mathrm{p}=.000$ and has a large kurtosis, $\mathrm{Z}=2.132, \mathrm{p}=.033$ ). This is most likely caused by a certain redundancy, since purpose is logically linked with success. Finally, the 
correlation between simplicity and mission exposure (security) is positively skewed, $\mathrm{Z}=3.168, \mathrm{p}=.002$.

\section{Discussion}

\section{Implications for the attacker - decisive and contextual principles}

Poor reliability may explain why the model received only partial support, but the indicators are theoretically valid. It could also be claimed that simplicity, speed and repetition were rarely violated, and since there is no (real) variation, there can be no correlation. However, there may be more to the result than first meets the eye. I will here assume that the result can at least in part be attributed to a fundamental difference between what can be described as "decisive" principles, i.e. security, purpose, and surprise, and the "contextual" principles simplicity, repetition, and to some degree, speed. It is argued that conceptual refinement may offer more adequate measurements (and consequently demonstrate significant effects), but available data do not allow for further tests in this study.

Violating "decisive" principles will immediately penalize an attacker regardless of the nature of the objective. Any mission is instantly jeopardized if security is broken, and it is redundant to state that an aborted mission or an altered objective implies that an initial objective will not be achieved. Finally, a smaller force is dependent on tactical surprise and is otherwise likely to fail. In short, these principles are largely a matter of either-or. This does not imply that "contextual" principles can be ignored; merely that simplicity, speed, and repetition are more ambiguous, possibly more elastic, and dependent on the nature of the objective and the particular "context" in which a task is conducted.

Rehearsing a particular mission is by definition "contextual" since the rehearsal considers a specific objective and specific requirements. It is not always possible to rehearse a particular mission and contingencies of how the situation may develop. As noted above, rehearsal can sometimes be substituted by a more general training and/or experience. In that sense, the 
results do not contradict McRaven's model, since patrol members had received adequate training and usually had previous combat experience.

It was noted above that there are two aspects to speed, i.e. the time spent in contact with the enemy at the objective, and the time spent in transition to the objective. However, there is also a third qualitative element that largely eludes quantification, i.e. whether an attacker is able to maintain the initiative. Relative superiority is dependent on a set of key events or prerequisites that must be accomplished before the opposing force is able to respond adequately. These are necessary but not sufficient conditions for success that are specific for a particular situation. In the aforementioned hypothetical example, when the attacker infiltrates an enemy stronghold, it may still be possible to achieve relative superiority if the force is discovered before all elements have deployed. If the attacker is able to sustain the momentum, i.e. acting faster than the defender can recover and respond, relative superiority may still be achieved. However, this is obviously dependent on the number and art of prerequisites that must be achieved, which is an aspect partly distinct from the mere time spent and associated with the principle of simplicity; the more prerequisites that must be accomplished in a given amount of time, the more difficult the task. It is also evident that the time as such spent after the point of vulnerability, even when the difficulty of the objective is disregarded, is likely to be inversely correlated with success. If merely this aspect were considered, speed could plausibly be a "decisive" principle, but since other aspects of speed depend on features of the actual objective, it is considered "contextual".

The transition phase may not always benefit from a fast execution, if enemy positions can be bypassed. The attacker may even have an opportunity to rectify and alter the approach, something that will rarely be possible after the point of vulnerability has been reached. Whereas time undoubtedly will begin to conspire against the attacker in the sense of an increased "friction of war" as soon as enemy territory is penetrated, an attacker may still benefit from a slower but safer transition to contact. This is the only plausible explanation to the contradictory correlations 
between the number of days spent in hostile territory and success as well as surprise reported in Table 1 . There are no data concerning the time spent in contact with the enemy for obvious reasons; patrols had more immediate concerns than checking their watches. However, it would seem that Finnish patrols rarely violated this aspect of "speed". Notably, a sole exception was a patrol tasked to hold a road to aid a Finnish counterattack, having to withdraw after enemy armour appeared (Saressalo 2010: 404). It would in any case seem counterintuitive and illogical to presume that a protracted engagement would benefit an attacker, unless it ensures the complete incapacitation of the defender. Although it cannot be assessed here, it seems rather obvious that time will be biased in favour of the defender, since the attacker will be more dependent on certain prerequisites, and hence, more exposed to the friction of war. This notion ties in with the principle of simplicity.

The contradictory result reported in Table 1, and the failure of subsequent analyses to demonstrate significant results, may suggest that the principle of simplicity demands further refinement. It should of course be noted that the measurement was crude, and did not fully account for whether the execution was kept simple, which is essential for how the principle has been defined, also by McRaven. However, there is a third aspect.

In one sense, simplicity is relative. A comparison of patrols may illustrate this. Patrol 17/1, achieving seven objectives (several instances of reconnaissance and derailing trains) during a single month in late summer 1941, conducted operations against a routed and retreating enemy, whereas several attempts by all detachments to capture prisoners failed during winter 1943-44. (In Appendix 1 these are listed as patrols 53/1 48/4; for details, see Saressalo 2010: 113-114, 314-339) Although other missions could hardly be described as "easy", taking prisoners was considered particularly difficult, especially in winter conditions. It demanded extensive skills, mental and physical endurance, and in particular, good luck. (Tikkanen 1996: 148) This was not merely an outcome of the enemy eventually having recovered, but also of very different prerequisites for success. The objectives of patrol 17/1 were 
moderately associated with one another, but the single objective of capturing a prisoner implied several prerequisites. First, the patrol had to surreptitiously infiltrate enemy territory. Second, the patrol would have to find a suitable place for an ambush, e.g. a road, where the enemy, thirdly, would pass in inferior numbers (if not a single person) and, fourthly, not fight back and refuse to be captured. Attempts to capture a prisoner implied to some extent ceding the initiative to the enemy, or at least being dependent on circumstances that could not be fully controlled, which also violates the qualitative aspect of speed. Finally, the patrol would have to successfully exfiltrate with a prisoner or immediately interrogate him. The more complex an operation is, the more prerequisites must be fulfilled, and the greater the "friction of war" is. Unfortunately, the data's limitations prevented assessment of alternative definitions of simplicity.

The notion that the prerequisites (or necessary key events) rather than the number of objectives is decisive does not contradict what is usually meant by simplicity; several objectives also imply that several prerequisites must be met and makes a simple execution more difficult. However, this is dependent on the actual context in which an operation takes place, which means that simplicity would, somewhat paradoxically, be a particularly difficult principle to define. Is a simple plan one that is less sensitive to unforeseen events, and how should a planner predict what in intelligence is known as the "unknown unknowns", apart from keeping the execution simple and speedy? But is a simple plan automatically less dependent on prerequisites than a complex one? The conditions that determine success or failure with regard to "contextual" principles may be even further obscured by the "fog of war" than the "decisive" principles that may immediately punish the unwary. Further research may accordingly gain from critical refinement of the contextual principles.

\section{Implications for the defender}

There are implications also for the defender. Since the triad of security, purpose and surprise appears decisive for the outcome, an alert intelligence is the first line of defence. Aggressive counter-patrolling will 
extend the area of vulnerability, reducing the time an attacker's transit can be made in relative security. This was duly noted by Finnish patrols as Soviet forces began to implement more effective counter-tactics in 1942. (Saressalo 2010: 158-159) Whereas counter-patrolling in contested areas is no military novelty, it is notable that the logic of relative superiority may also aid the defender. If ambushed during the transit or facing aggressive counterattacks even by small units, the attacker's capability of continuing the mission may be degraded. Although it cannot be supported by these data, it seems plausible that time is biased against the attacker, and even a less than well-prepared counterattack may cause too much "friction" to establish relative superiority. Accordingly, whereas an attacker must have a well thought-out plan of action, the situational logic may favour even less effective countermeasures by the defender.

Analogous findings have been reported from a wide area, with the caveat that the counterattacking force must have sufficient training and equipment, ranging from the discussion concerning the US response to the 11 September 2012 terror attack against the diplomatic mission in Libya (Housley 2013; Lawrence 2013), the terrorist attack in Mumbai on 26 November 2008 (Badri-Maharaj 2009; Rabasa et al. 2009: 10-11), to aggressive responses against "active shooters" at school shooting incidents (O'Rourke 2010: 47-48; Ergenbright \& Hubbard 2012: 30-37, 131-132), and even recommendations that intended victims as a last resort might attempt to attack the active shooter (Department of Homeland Security 2014: 4). Finally, an attacker may be denied accurate intelligence, not only passively by maintaining security, but also actively through deception and decoys.

The contextual principles imply certain warnings for a defender. If simplicity actually is a somewhat elastic principle, a defender should not automatically assume that complex schemes are unlikely to be pulled off. History has repeatedly proven that a "can't happen here"-attitude is likely to be punished. The terror attacks on September 11, 2001, demonstrate that even a long transition time and build-up may be viable. Finally, although a potential opponent has not done something before, it does not 
automatically follow that the opponent is unprepared to do the unexpected. These notions tie in with the age old maxim that an opponent should never be underestimated, and to overcome an attack, an aggressive, active and imaginative defence is essential.

\section{Conclusion}

The result offers partial support for Admiral McRaven's model of special operations principles, and arguments were presented as to why it should not be refuted to the extent that data failed to offer support. The "decisive" principles security, purpose, and surprise, are principles in the strictest sense, based on their direct impact on the likelihood of success. They form a core that most likely pertains almost identically to each situation. Special operations cannot succeed without surprise, security that guarantees surprise, and commitment.

It was furthermore assumed that the more unexpected results could not solely be attributed to weaknesses in measurement or the circumstance that "contextual" principles were rarely violated, but rather that these principles, i.e. simplicity, speed, and repetition, require further conceptual development. The lack of significant effects would, based on this interpretation, be an outcome of a failure of the principles, as they are usually defined, to account for the essential properties of the context and the nature of the object. A particular area of interest concerns the key events and prerequisites that must be achieved in order to ensure relative superiority, which seem to tie in very closely with the principle of simplicity. The result (or rather lack thereof) suggests that it is not necessarily the scope of a mission, but the number of prerequisites that must be achieved, and whether these depend on one another that is essential. Repetition may serve to identify some overlooked preconditions; apart from ensuring necessary skills and ability to adapt to a situation, repetition may also identify hidden prerequisites.

However, there will inevitably be some "unknown unknowns" regardless of planning and preparation, although the latter will reduce their potential 
impact. Ironically, these aspects tie in with von Clausewitz's view on the unpredictable nature of battle, an aspect that is particularly salient for a form of operations he frowned at. It is conceivable that if he faced contemporary conditions, von Clausewitz might have seen it adequate to revise his views. Regardless of whether the principles of war have changed or not, the centres of gravity certainly have. Whereas nineteenth century armies may have been less vulnerable to small group tactics, contemporary societies and armed forces have weak spots, where a small group of attackers can cause disproportionate damage.

\section{References}

Alger, J. I. (1982). The Quest for Victory. The History of the Principles of War. Westport, Conn.: Greenwood Press.

Badri-Maharaj, S. (2009). The Mumbai Attacks - Lessons to be Learnt from the Police Response. Journal of Defence Studies 3(2), 145156.

Bryant, D. J. (2004). Modernizing Our Cognitive Model. Toronto: Defence Research Development Canada - Toronto, Judgment and Decision-Making Group. [Online] http://oai.dtic.mil/oai/oai?verb=getRecord\&metadataPrefix $=$ html\&i dentifier=ADA465834 [Accessed 22 April 2014]

Clausewitz, C. von. (2007). On War. Oxford: Oxford University Press.

Collins, J. M. (2002). Military Strategy. Principles, Practices and Historical Perspectives. Washington, D.C.: Brassey's Inc.

Department of Homeland Security. (2014). Active Shooter. How to Respond. [Online] http://www.dhs.gov/publication/active-shooterhow-respond [Accessed 4 May 2014]

Department of the Army. (2011) Field Manual FM 3-0. Operations. Washington, DC. Revised version of the 2008 Field Manual. [Online]. http://downloads.army.mil/fm3-0/FM3-0.pdf [Accessed 4 May 2014]

Department of the Army. (2012). Army Doctrine Reference Publication ADRP 3-0. Unified Land Operations. Washington, DC. [Online]. 
http://armypubs.army.mil// doctrine/DR_pubs/dr_a/pdf/adrp3_0.pdf [Accessed 4 May 2014]

Echevarria, A. J. II. (2005). "Principles of War or Principles of Battle?"

Pp. 58-78 in Anthony D. McIvor (Ed.) Rethinking the Principles of War. Annapolis, Maryland: Naval Institute Press.

Ergenbright, C. E ; Hubbard, S. K. (2012). Defeating the Active Shooter: Applying Facility Upgrades in Order to Mitigate the Effects of Active Shooters in High Occupancy Facilities. Monterey, CA.: Naval Postgraduate School [Online] http://oai.dtic.mil/oai/oai?verb=getRecord\&metadataPrefix=html\&i dentifier=ADA562724 [Accessed 4 May 2014]

Ettrich, B. B. (2005). The Principles Of War: Are They Still Applicable? Monterey, CA.: Naval Postgraduate School. [Online] http://oai.dtic.mil/oai/oai?verb=getRecord

\&metadataPrefix $=\mathrm{html} \&$ identifier $=$ ADA435689 [Accessed 4 May 2014]

Glantz, D. M. (1991a). The Soviet Conduct of Tactical Maneuver. Spearhead of the Offensive. London: Frank Cass.

Glantz, D. M. (1991b). Soviet Military Operational Art. In Pursuit of Deep Battle. London: Frank Cass.

Hammes, T. X. (2005). "Rethinking the Principles of War. The Future of Warfare." Pp. 263-278 in A. D. McIvor (Ed.) Rethinking the Principles of War. Annapolis, Maryland: Naval Institute Press.

Hammond, G. T. (2005). "The U.S. Air Force and the American way of War". Pp. 109-126 in A. D. McIvor (Ed.) Rethinking the Principles of War. Annapolis, Maryland: Naval Institute Press.

Harrison, R. W. (2001). The Russian Way of War. Operational Art 1904-1940. Lawrence: University Press of Kansas.

Hesterberg, T., Monaghan, S., Moore, D. S., Clipson, A. \& Epstein, R. (2003). "Bootstrap methods and permutation tests". Separate companion chapter 18 to Moore, D. S. \& McCabe, G. P. Introduction to the practice of statistics. New York: Freeman. [Online: 10 March 2005] http://statweb.stanford.edu/ tibs/stat315a/ Supplements/bootstrap.pdf [Accessed 25 May 2014] 
Hoffman, F. G. (2005). "Principles for the Savage Wars of Peace." Pp. 299-320 in A. D. McIvor (Ed.) Rethinking the Principles of War. Annapolis, Maryland: Naval Institute Press.

Housley A. (2013). Special forces could've responded to Benghazi attack, whistle-blower tells Fox News. Fox News. Published April 30, 2013.

[Online] http://www.foxnews.com/politics/2013/04/30/special-ops-benghaziwhistleblower-tells-fox-news-government-could-have/ [Accessed 4 May 2014]

Irincheev, B. \& Repnikov, P. 2013. Kaukopartio-operaatio Petrovskij Jam. Legendaarinen sissi-isku vai sotarikos? Juva: Minerva.

Johnson, R., Whitby, M. \& France, J. (2010). How to Win on the Battlefield. London: Thames \& Hudson.

Jomini, A. H. de. (2007). The Art of War. Rockville, MD.: Arc Manor.

Lanir, Z. 1993. "The 'Principles of War' and Military Thinking". Journal of Strategic Studies, 16(1), 1-17.

Lawrence, C. (2013). Panetta on Benghazi attack: 'Could not put forces at risk'. CNN. Published October 26, 2012. [Online] http://security.blogs.cnn.com/2012/10/26/panetta-on-benghaziattack-could-not-put-forces-at-risk/comment-page-1/ [Accessed 4 May 2014]

Malay, P. (2007). Principles of War in the 21st Century. Carlisle, PA.: U.S. Army War College. [Online] http://oai.dtic.mil/oai/oai?verb=getRecord\&metadataPrefix $=$ html\& identifier=ADA467296 [Accessed 4 May 2014]

Marr, J. J. (2001). The Military Decision Making Process: Making Better Decisions Versus Making Decisions Better. Fort Leavenworth, KS: School of Advanced Military Studies, United States Army Command and General Staff College. [Online] http://oai.dtic.mil/oai/oai?verb=getRecord\&metadataPrefix=html\&i dentifier=ADA387136 [Accessed 22 April 2014]

Marttinen, E. \& Tikkanen, J. (2002). Olimme Päämajan kaukopartiomiehiä. Juva: WSOY 
McRaven, W. H. (1995). SPEC OPS. Case Studies in Special Operations Warfare: Theory and Practice. New York: Ballantine Books.

Metz, S. (2005). "Small Wars. From Low Intensity Conflicts to Irregular Challenges." Pp. 279-298 in A. D. McIvor (Ed.) Rethinking the Principles of War. Annapolis, Maryland: Naval Institute Press.

Ministry of Defence, (2010). Army Doctrine Publication. Operations. Shrivenham

[online] https://www.gov.uk/government/uploads/system/uploads/attachmen t_data/file/33695/ADPOperationsDec10.pdf [Accessed 4 May 2014]

Morris, D. R. (2009). "Surprise and Terrorism: A Conceptual Framework." The Journal of Strategic Studies 32(1), 1-27.

O'Rourke, S. (2010). The Emergent Challenges for Policing Terrorism: Lessons from Mumbai, Conference Proceeding. Perth: School of Computer and Information Science, Edith Cowan University. [Online] http://ro.ecu.edu.au/act/5/ [Accessed 4 May 2014]

Osborne, J. W., \& Waters, E. (2002). "Four assumptions of multiple regression that researchers should always test." Practical Assessment, Research, and Evaluation 8(2). [Online] http://pareonline.net/getvn.asp?v=8\&n=2 [Accessed 13 September 2014].

Phillips, J., McDermott, P. L., Thordsen, M., McCloskey, M \& Klein, G. (1998). Cognitive Requirements for Small Unit Leaders in Military Operations in Urban Terrain. U.S. Army Research Institute for the Behavioral and Social Sciences, Research Report 1728. [Online] http://oai.dtic.mil/oai/oai?verb=getRecord\&metadata Prefix $=$ html\&identifier $=$ ADA355505 [Accessed 22 April 2014]

Rabasa, A., Blackwill, R. D., Chalk, P., Cragin, K., Fair, C. C., Jackson, B. A., Jenkins, B. M., Jones, S. G., Shestak, N. \& Tellis, A. J. (2009). The Lessons of Mumbai. Santa Monica, CA.: RAND Corporation. [Online] http://www.dtic.mil/get-trdoc/pdf?AD=ADA493061 [Accessed 4 May 2014] 
Saressalo, L. (2010). Päämajan kaukopartiot jatkosodassa. Helsinki: Werner Söderström Oy.

Scales, R. H. (2005). “The Second Learning Revolution.” Pp. 41-57 in A. D. McIvor (Ed.) Rethinking the Principles of War. Annapolis, Maryland: Naval Institute Press.

Tikkanen, P. H. (1996). Päämajan sissit. Päämajan kaukopartioiden suorittamia erikoistehtäviä vihollisen selustassa. Hämeenlinna: Karisto Oy.

Tikkanen, P. H. (2004). Valiosissit kaukopartiossa. Hämeenlinna: Karisto Oy.

Tovy, T. (2009). "Are the Principles of War Applicable to Special Task Forces? Operation Gothic Serpent Re-examined". The RUSI Journal 154(2), 56-62.

United States Special Operations Command. (2011). Joint Publication 3-05. Special Operations. MacDill AFB, Fl.. [Online] http://www.dtic.mil/doctrine/new_pubs/jp3_05. pdf [Accessed 6 October 2013]

Ångström, J. \& Widén, J. J. (2012). “Adopting a Recipe for Success: Modern Armed Forces and the Institutionalization of the Principles of War", Comparative Strategy 31(3), 263-285. 


\section{Appendix 1. Patrols and variable values}

Note: the patrol number consists of two parts, i.e. the consecutive number of the patrol and the detachment in question. Data concerning individual patrols have been obtained primarily from Saressalo, L. (2010). Päämajan kaukopartiot jatkosodassa. Helsinki: Werner Söderström Oy. Additional data have been obtained from: Marttinen, E. \& Tikkanen, J. (2002). Olimme Päämajan kaukopartiomiehiä. Juva: WSOY, pp. 85-87, 103-111, 123-134, 137-156, 197-206, 225-260, 281-300 (patrols 19/3, 24/3, 28/3, 30/3, 45/3, 48/3, 56/3, 59/3, 61/3, 62/3, 62/4-71/3, and the Petrovskij Jam raid); Tikkanen, Pentti H. 1996. Päämajan sissit. Päämajan kaukopartioiden suorittamia erikoistehtäviä vihollisen selustassa. Hämeenlinna: Karisto Oy, pp. 138-148, 277-417 (patrols 12/1, 18/3, 27/2, 46/3); Tikkanen, P. H. 2004. Valiosissit kaukopartiossa. Hämeenlinna: Karisto Oy, pp. 17-65, 97-113, 160-234, 251-266 (patrols 11/2, 16/2, 27/2, 37/2, 19/3, the Petrovskij Jam raid, and Task Force Kaleva). In case of minor inconsistencies, e.g. with regard to patrol size and dates, I have used the data presented by Saressalo. Such cases are denoted with an *)

Variables: I=Success; II=Surprise; III=Change of objective or ${ }^{\text {a) }}$ aborted mission (Purpose), IV=Number of objectives (Simplicity). V=Mission exposed (Security). VI=Proportion of experienced members (Repetition). VII=Days spent in hostile territory (Speed)

\begin{tabular}{|c|c|c|c|c|c|c|c|c|}
\hline $\begin{array}{l}\text { Patrol } \\
\text { number }\end{array}$ & $\mathbf{I}$ & II & III & IV & $\mathbf{V}$ & VI & \multicolumn{2}{|c|}{ VII Dates } \\
\hline $8 / 1$ & 0 & 0 & $1^{\text {a) }}$ & 2 & 1 & .3 & 2 & 25-26 Jun 1941 \\
\hline $9 / 1$ & 0 & 0 & $1^{\text {a) }}$ & 2 & 1 & 0 & 1 & 27 Jun 1941 \\
\hline $12 / 1 *$ & .5 & 1 & 0 & 2 & 0 & .4 & 13 & 30 Jun-12 Jul 1941 \\
\hline $13 / 1$ & 1 & 1 & 0 & 7 & 0 & .6 & 21 & 30 Jun-20 Jul 1941 \\
\hline $16 / 1$ & 1 & 1 & 0 & 2 & 0 & .8 & 19 & 23 Jul-11 Aug 1941 \\
\hline $17 / 1$ & 1 & 1 & 0 & 7 & 0 & .7 & 30 & 23 Jul-22 Aug 1941 \\
\hline $18 / 1$ & .7 & 1 & 1 & 3 & 0 & 1 & 4 & 5-8 Aug 1941 \\
\hline $19 / 1$ & 1 & 1 & 0 & 2 & 0 & 1 & 12 & 16-27 Aug 1941 \\
\hline
\end{tabular}




$\begin{array}{lllllllll}20-21 / 1 & .8 & 1 & 1 & 4 & 0 & .8 & 5 & \text { 30Aug-3 Sept 1941 } \\ 4 / 2 & 1 & 1 & 0 & 1 & 0 & 1 & 17 & \text { 28 Jun-14 Jul 1941 } \\ 5 / 2 & 1 & 0 & 0 & 1 & 0 & .2 & 9 & \text { 20-28 Jul 1941 } \\ 7 / 2 & 0 & 1 & 0 & 2 & 0 & .4 & 11 & \text { 3-13 Aug 1941 } \\ 8 / 2 & 0 & 0 & 1^{\text {a) }} & 1 & 1 & 1 & 1 & \text { Appr 15 Aug 1941 } \\ 9 / 2 & 0 & 0 & 1^{\text {a) }} & 1 & 1 & 1 & 1 & \text { Appr 15 Aug 1941 } \\ 10 / 2 & 0 & 1 & 0 & 2 & 0 & .6 & 8 & \text { 1-8 Sep 1941 } \\ 11 / 2 * & 1 & 1 & 1 & 3 & 1 & .8 & 5 & \text { 4-8 Sep 1941 } \\ 14 / 2 & 1 & 1 & 0 & 2 & 0 & 1 & 11 & \text { 25 Sep-5 Oct 1941 } \\ 13 / 3 & 1 & 1 & 0 & 3 & 0 & 1 & 16 & \text { 1-16 Aug 1941 } \\ 15 / 3 & 1 & 1 & 0 & 2 & 0 & .6 & 14 & \text { 17-30 Aug 1941 } \\ 17 / 3 & 1 & 1 & 0 & 1 & 0 & 1 & 13 & \text { 15-27 Sep 1941 } \\ 18 / 3 * & 1 & 0 & 0 & 2 & 1 & 1 & 10 & \text { 18-27 Sep 1941 } \\ 19 / 3 * & 1 & 1 & 0 & 2 & 1 & .8 & 18 & \text { 6-23 Oct 1941 } \\ 24 / 3 * & 1 & 0 & 0 & 2 & 1 & .3 & 4 & \text { 4-7 Dec 1941 } \\ 13 / 4 & 1 & 1 & 0 & 2 & 0 & 1 & 9 & \text { 10-18 Aug 1941 } \\ 34 / 1 & 1 & 1 & 0 & 2 & 0 & .8 & 11 & \text { 8-18 Jan 1942 } \\ 35 / 1 & .5 & 0 & 1 & 2 & 0 & .4 & 8 & \text { 20-27 Jan 1942 } \\ 19 / 2 & 0 & 0 & 1 & 2 & 1 & .9 & 11 & \text { 10-20 Dec 1941 } \\ 20 / 2 & .5 & 1 & 1 & 2 & 0 & .2 & 8 & \text { 12-19 Dec 1941 } \\ 21 / 2 & 0 & 0 & 1 & 2 & 1 & .7 & 2 & \text { Jan 1942 } \\ 25 / 3 & .5 & 0 & 0 & 1 & 0 & .9 & 3 & \text { 22-24 Dec 1941 } \\ 27 / 3 & .5 & 1 & 0 & 1 & 0 & .7 & 7 & \text { 6-12 Jan 1942 } \\ 28 / 3 & 0 & 1 & 1 & 1 & 0 & .3 & 4 & \text { 14-17 Jan 1942 } \\ 30 / 3 & 1 & 1 & 0 & 2 & 0 & .6 & 7 & \text { 16-22 Jan 1942 } \\ 31 / 3 & 0 & 0 & 1 & 2 & 1 & .6 & 3 & \text { 5-7 Feb 1942 } \\ 34 / 3 & 1 & 1 & 0 & 2 & 1 & 1 & 9 & \text { 9-17 Mar 1942 } \\ 35 / 3 & 0 & 0 & 1 & 2 & 1 & 1 & 2 & \text { 8-9 Apr 1942 } \\ 19 / 4 & 0 & 1 & 0 & 2 & 0 & .7 & 8 & \text { 13-20 Dec 1941 } \\ 27 / 2 & 1 & 1 & 0 & 4 & 0 & .9 & 45 & \text { 26 Jul-9 Sep 1942 } \\ 29 / 2 & .7 & 1 & 0 & 3 & 0 & .8 & 29 & \text { 31Aug-28Sep 1942 } \\ 38 / 3 & .2 & 0 & 1 & 5 & 0 & .5 & 42 & \text { 9 Jul-19 Aug 1942 } \\ 45 / 3 * & .5 & 1 & 0 & 2 & 0 & 1 & 12 & \text { 3-14 Oct 1942 } \\ 46 / 3 & 1 & 1 & 0 & 2 & 1 & 1 & 20 & \text { 3-22 Oct 1942 } \\ 30 / 4 & 1 & 1 & 0 & 2 & 1 & .8 & 10 & \text { 29 Sep-8 Oct 1942 }\end{array}$




$\begin{array}{lllllllll}31 / 2 & 0 & 0 & 1 & 4 & 1 & .5 & 3 & \text { Mar 1943 } \\ 47 / 3 & 0 & 0 & 1 & 1 & 1 & .8 & 3 & \text { 15-17 Jan 1943 } \\ 48 / 3 & 0 & 0 & 0 & 1 & 0 & .8 & 7 & \text { 15-21 Jan 1943 } \\ 49 / 3 & 1 & 1 & 0 & 1 & 0 & 1 & 7 & \text { 17-23 Jan 1943 } \\ 51 / 3 & 0 & 0 & 1 & 1 & 1 & .9 & 0 & \text { Apr 1943 } \\ 33 / 4 & 0 & 0 & 1 & 2 & 1 & .4 & 3 & \text { 12-14 Jan 1943 } \\ 34 / 4 & 1 & 1 & 0 & 2 & 0 & .6 & 8 & \text { 12-19 Jan 1943 } \\ 35 / 4 & 0 & 0 & 1 & 2 & 1 & .8 & 20 & \text { 16 Feb-7 Mar 1943 } \\ 49 / 1 & 1 & 1 & 0 & 3 & 1 & .6 & 33 & \text { 16 Jun-18 Jul 1943 } \\ 33 / 2 & 0 & 0 & 1 & 1 & 1 & .6 & 7 & \text { 8-14 Jul 1943 } \\ 34 / 2 & .5 & 0 & 1 & 2 & 1 & .7 & 10 & \text { 8-17 Jul 1943 } \\ 35 / 2 & 1 & 1 & 0 & 2 & 0 & .9 & 29 & \text { Jul 1943 } \\ 36 / 2 & 1 & 1 & 1 & 2 & 0 & 1 & 23 & \text { 28 Sep-20 Oct } 1943 \\ 37 / 2 & 1 & 1 & 0 & 4 & 0 & .7 & 11 & \text { 26 Sep-6 Oct } 1943 \\ 53 / 3 & 0 & 0 & 1 & 2 & 1 & .9 & 8 & \text { 24 Jun-1 Jul 1943 } \\ 56 / 3 & 0 & 0 & 1 & 2 & 1 & .9 & 31 & \text { 29 Jun-29 Jul 1943 } \\ 57 / 3 & 1 & 1 & 0 & 1 & 0 & 1 & 13 & \text { 12-24 Sep 1943 } \\ 58 / 3 & .5 & 1 & 0 & 3 & 0 & .9 & 22 & \text { 25 Sep-16 Oct } 1943 \\ 59 / 3 * & .5 & 1 & 1 & 2 & 0 & .9 & 12 & \text { 5-16 Oct 1943 } \\ 47 / 4 & .2 & 1 & 1 & 9 & 0 & .9 & 6 & \text { 1-6 Oct 1943 } \\ 53 / 1 & 0 & 0 & 1 & 2 & 1 & .3 & 2 & \text { 13-14 Feb 1944 } \\ 54 / 1 & 0 & 0 & 0 & 1 & 0 & 1 & 3 & \text { 21-23 Feb 1944 } \\ 55 / 1 & 0 & 0 & 1 & 1 & 0 & 1 & 3 & \text { 11-13 Mar 1944 } \\ 56 / 1 & 0 & 0 & 0 & 1 & 1 & .7 & 7 & \text { 11-17 Mar 1944 } \\ 38 / 2 & 0 & 0 & 0 & 1 & 0 & .8 & 3 & \text { Jan 1944 } \\ 39 / 2 & 0 & 0 & 1 & 1 & 0 & 1 & 4 & \text { Janu 1944 } \\ 40 / 2 & 0 & 0 & 0 \text { a) } & 1 & 0 & .7 & 2 & \text { Janu 1944 } \\ 60 / 3 & 0 & 0 & 1 \text { a) } & 1 & 1 & .5 & 8 & \text { 17-24 Jan 1944 } \\ 61 / 3 * & 0 & 0 & 0 & 1 & 0 & .7 & 2 & \text { 31 Jan-2 Feb 1944 } \\ 62 / 3 * & 0 & 0 & 0 & 1 & 0 & .7 & 5 & \text { 2-6 Feb 1944 } \\ 64 / 3 & 0 & 0 & 0 & 1 & 0 & 1 & 5 & \text { 14-18 Mar 1944 } \\ 48 / 4 & 0 & 0 & 1 & 2 & 1 & .8 & 7 & \text { 22-28 Jan 1944 } \\ 51 / 4 & .5 & 1 & 1 & 4 & 0 & .9 & 7 & \text { 9-15 Feb 1944 } \\ 54 / 4 & 1 & 1 & 0 & 1 & 0 & 1 & 6 & \text { 15-20 Mar 1944 } \\ 42 / 2 & 0 & 0 & 0 & 1 & 0 & 1 & 4 & \text { 15-18 Jun 1944 }\end{array}$




$\begin{array}{lllllllll}51 / 2 & 0 & 1 & 0 & 1 & 0 & .9 & 4 & \text { Aug 1944 } \\ 62 / 4 ; 71 / 3^{*} & 1 & 1 & 0 & 3 & 0 & .9 & 11 & \text { 3-13 Aug 1944 } \\ 73 / 3 ; 63 / 4 & .5 & 0 & 0 & 2 & 0 & 1 & \text { 28 } & \text { 6 Aug-2 Sep 1944 } \\ 53 / 2 ; 69 / 1 & 1 & 1 & 0 & 2 & 1 & .7 & 25 & \text { 13 Aug-6 Sep 1944 } \\ \text { A) } & 1 & 1 & 0 & 6 & 0 & .8 & 9 & \text { 8-16 Feb 1942 } \\ \text { B) } & .8 & .8 & 0 & 5 & 0 & .8 & 5 & \text { 27-31 Mar 1944 } \\ \text { A) The Petrovskij Jam raid } \\ \text { B) Task Force Kaleva }\end{array}$

